\title{
El disfraz varonil en el teatro español de los Siglos de Oro
}

\author{
M. José Rodríguez-Campillo, \\ M. Dolores Jiménez-López, \\ Gemma Bel-Enguix
}

Universitat Rovira i Virgili

\section{Introducción}

La literatura está llena de voces femeninas y masculinas y, por tanto, codificada en múltiples discursos sexualizados. La diferencia sexual, que presenta un componente biológico -previo a toda estructuración lingüística o retórica-, responde a una formación social y cultural; esto es, sufre un proceso de semiotización. La asignación de estereotipos relacionados con el género está presente a lo largo de la historia en todas las culturas, y los Siglos de Oro de la literatura española no son una excepción.

La mujer de los Siglos de Oro tiene prohibidos una serie de comportamientos (vengarse, batirse en duelo, conquistar...) relacionados con una retórica masculina también vetada a las mujeres. Para vencer esas prohibiciones, la estrategia es disfrazarse de hombre. Los personajes disfrazados acomodan discurso y conducta al personaje que encarnan, provocando una situación compleja y ambigua que surge de la preocupación por el decoro. La mujer en el teatro de los Siglos de Oro se viste de hombre para poder hablar y comportarse como un hombre. Disfrazada de hombre, puede recurrir a la violencia, acercarse a la cultura, batirse en duelo o utilizar expresiones no adecuadas a las mujeres. Solo disfrazándose, la mujer puede expresar su 
odio, su furia o su sed de venganza, ya sea mediante el lenguaje o a través de los hechos.

Este artículo pretende estudiar el cambio en el comportamiento y en el lenguaje que el disfraz varonil provoca en las mujeres en las comedias de los Siglos de Oro. En concreto, se analizan algunos personajes travestidos creados por autores masculinos y femeninos. Con esta comparación se pretende demostrar el distinto uso que de un mismo tópico -el disfraz varonil- hacen dramaturgos y dramaturgas de la misma época. Las diferencias observadas en el uso del disfraz varonil sugieren la necesidad de analizar de manera más profunda las implicaciones que se derivan del empleo de este recurso cuando se encuentra en obras escritas por mujeres.

\section{La situación de la mujer en los Siglos de Oro}

El género es una construcción cultural basada en los usos y costumbres de una sociedad. Las sociedades asignan roles a las personas por el hecho de ser hombres o mujeres. En la mayoría de las sociedades, las características que se asignan a un género se le niegan al otro. Por ello se forman estereotipos respecto a las distintas cualidades que poseen uno y otro género. Así, por ejemplo, desde tiempos ancestrales, se asigna al género masculino la fuerza y, por el contrario, al femenino, la debilidad. Esta asignación de estereotipos ha subsistido hasta hace pocos años. Las bases del cuestionamiento de estos estereotipos se encuentran ya en el siglo XVII y, sobre todo, en el siglo XVIII. Hasta entonces, se creía que Dios había creado a hombres y mujeres de distinta forma, para así poder desempeñar distintas tareas sociales. Por tanto, ambos debían tener una educación distinta: el hombre debía aprender todo lo que estaba a su alcance con respecto a las matemáticas, las ciencias, las letras...; la mujer, en cambio, tenía prohibido el acceso a la educación, y solo se le enseñaba a coser y a llevar una casa.

Bien entrado el siglo XVII, las mujeres se atreven a intentar tener acceso a la cultura, no solo como lectoras de obras, sino como escritoras. Ahora bien, es tanto el miedo que tienen a que la sociedad en la que viven les vete este derecho y les cuestione su trabajo que la mayoría escribe bajo pseudónimo u ocultándose tras sus maridos o parientes masculinos. Algunas de ellas no se atreven a sacar a la luz lo que ellas mismas denominan sus "borrones", como muestra el siguiente ejemplo de María de Zayas y Sotomayor en el prólogo "Al que leyere" de sus Novelas amorosas y ejemplares (1637): 
Quien duda... que habrá muchos que atribuyan a locura esta virtuosa osadía de sacar a la luz mis borrones, siendo mujer, que, en opinión de algunos necios, es lo mismo que una cosa incapaz.

Las mujeres tenían muy asimilado el rol que la sociedad les había impuesto como representantes del género femenino: debían estar en casa, cosiendo, rezando o haciendo las tareas del hogar y ocupándose de los hijos. Ellas eran el sexo débil y, por tanto, no debían salirse de los márgenes que la sociedad les había trazado. Incluso, después de publicarse el Informe Quintana (1813), en el que se insistía en que todos los ciudadanos (hombres y mujeres) debían recibir una educación, se seguía cuestionando la conveniencia de que la mujer accediese a esa educación. Sin embargo, aunque de forma muy minoritaria, las señoras de la aristocracia de la época empiezan a defender la necesidad de instruir a las mujeres de la misma manera que a los hombres, y lo justifican citando los beneficios que ello podía reportar a los mismos hombres, ya que estas mujeres, que son madres, son las primeras educadoras de los niños (entre los cuales se encuentran, por supuesto, los hijos varones del matrimonio). Pero este objetivo se logra de distinta manera en los distintos países. En Estados Unidos y los países vinculados al protestantismo, por ejemplo, se implantan escuelas mixtas donde las mujeres pueden acceder de forma abierta a la cultura; sin embargo, en los países europeos vinculados al catolicismo tal acceso era aún algo raro y minoritario.

Los roles asignados a uno y otro sexo son continuamente redefinidos por la sociedad, esto es, no son estables y se van modificando en relación con los cambios sociales, demográficos, etc. Con el Renacimiento, la mujer toma conciencia de que la inferioridad con respecto al hombre es solo un mito. Esta idea llevará a la mujer a reafirmarse en sus derechos y a exigir la igualdad con los hombres. El humanismo, la Contrarreforma y, en definitiva, el nuevo pensamiento de la época crean la necesidad de redefinir o reconsiderar el papel de la mujer en la sociedad, pero lo hacen de manera distinta a como le hubiera gustado a la mujer. De hecho, si estos tratados de perfección dedicados a las mujeres se analizan detalladamente, se llega a la conclusión de que, en definitiva, de lo que se trata es de volver a relegar a la mujer al ámbito doméstico y de hacer un tratado orientativo, desde el discurso moral dominante, para decir a la mujer cuál era su verdadero sitio en la sociedad (cf. Ferrer Valls, 2006).

El humanismo, con Erasmo a la cabeza, convirtió el matrimonio en la única salida para la mujer de la época. Se quería una mujer que no causara 
problemas, que estuviera callada y que obedeciera en todo. Entre las virtudes destacables de la mujer figura la castidad, como pone de manifiesto el siguiente texto extraído de De institutione feminae christianae, de Juan Luis Vives (1492 1540):

Lo primero de todo sabrá la mujer cristiana que la principal virtud de la mujer es la castidad, la cual, única y todo, suple todas las restantes virtudes. Si la tuviere ella, nadie busca las otras, y si faltare ella, ninguno se satisface de las otras.

Vives 1990: 54

No pasa tanta necesidad la doncella de ser bien hablada, como de ser buena y honesta y sabia. Porque no es cosa muy fea a la mujer callar, y es muy fea no conocer el bien y abominable obrar el mal.

Vives 1990: 27

La misma idea la encontramos en los Coloquios matrimoniales (1550) de Pedro Luján:

Cosa es de notar y de donaire ver que muchas mujeres presumen de decidoras, y graciosas y mofadoras, el cual oficio no querría yo que lo dependiesen, ni menos que lo usasen, porque lo que en los hombres llamamos gracia en las mujeres llamamos chocarrería. La mujer que tiene gravedad no sólo no ha de boquear, ni pensar las cosas ilícitas y deshonestas, más las lícitas y honestas si no son muy necesarias porque la mujer jamás yerra callando y muy poquitas acierta hablando.

También debemos referirnos a La perfecta casada (1583), de Fray Luis de León, en la que se enumeran los distintos tipos de mujeres y se describe el ideal de mujer:

[...] Es justo que se precien en callar todas, así aquellas a las que les conviene encubrir su poco saber, como aquellas que pueden sin vergüenza descubrir lo que saben; porque en todas es, no sólo condición agradable, sino virtud debida, el silencio y el hablar poco [...]. Porque, así como la naturaleza hizo a las mujeres para que encerradas guardasen la casa, así las obliga a que cerrasen la boca.

Fray Luis de León, 1950: 239.

Interesante resulta la opinión de Juan de Zabaleta, en Errores celebrados (1653), sobre las escritoras: 
La mujer poeta es el animal más imperfecto y más aborrecible de cuantos forman la naturaleza.

Zabaleta 1972: 44.

Los ejemplos anteriores dan cuenta de la consideración de la mujer en los Siglos de Oro y justifican determinadas estrategias que se veían obligadas a utilizar las dramaturgas de los Siglos de Oro para revelarse contra los estereotipos asignados, por la sociedad de su época, al género femenino.

\section{La cuestión del honor en el teatro de los Siglos de Oro}

El honor -la dignidad del individuo- y la honra -el respeto que le debe la sociedad-son temas que desarrollaron un sistema de valores, actitudes, ideales y conducta social que aparece extensamente ejemplificado en los dramas de la época. El tema del honor como motivo dramático se deriva de un concepto que evoluciona desde la Edad Media hasta llegar al siglo XVI. La cuestión de la honra había resultado muy atractiva (temática y dramáticamente) para los comediógrafos españoles del siglo XVI. Fue Torres Naharro uno de los primeros en introducir el tema del honor en su Comedia Himenea. Más tarde, Lope de Vega recomendó el uso del tema de la honra en los dramas de la época como poderoso estímulo para el público: "[...] los casos de honra son mejores, / porque mueven con fuerza a toda gente" (vv. 327-328). Y, a partir de él, raro era el drama que no incluía dicho tema en su génesis.

Si una mujer era deshonrada, solo un hombre podía restituirle su honor a través de la venganza de la afrenta. Ella por sí sola no podía hacer nada para recuperar el honor perdido. Por ello, cuando las mujeres querían asumir el papel de propias vengadoras de su honra, lo único que podían hacer en esa época era disfrazarse de hombres, esto es, adquirir un rol masculino. Debían cambiar su género para que sus acciones no fueran mal vistas por la sociedad en que vivían. Este cambio de género aparece reflejado en el teatro de la época a través de la técnica del disfraz varonil.

\section{El disfraz varonil}

El recurso o motivo del disfraz varonil consistía en que la mujer se disfrazara de hombre para que el público que iba a ver representada la obra 
disfrutara con ello. El público, a diferencia de los personajes de la obra, era consciente de la estrategia. Con ello, se generaban enormes enredos y equívocos, muy del gusto de la época.

La técnica del galán fingido permitía a las mujeres introducirse desapercibidas en un mundo poblado de hombres, introducirse en sus mentalidades y en sus costumbres. La introducción de una mujer en el universo masculino resultaba paródica, sobre todo para los comediógrafos y el público de una época en que las mujeres tenían prohibido escribir y representar (como actrices) obras de teatro.

La mujer que aparece en escena en las obras de los Siglos de Oro no se viste de hombre porque sí; lo hace por un motivo particular (peregrinación, venganza...), para luego reasumir siempre su condición femenina. El disfraz es el medio utilizado, es el resultado de una conducta deseada con un fin específico, generalmente de provecho para el mismo personaje. Una vez conseguidos sus propósitos, se desvisten, recuperando otra vez su rol o papel femenino. Es una revelación voluntaria de su secreto, que hacen cuando ellas quieren, ante quien quieren y como quieren.

Este recurso se va a poner de moda a partir del teatro de Lope, quien recomienda este procedimiento en su famoso Arte nuevo de hacer comedias en este tiempo, con la única finalidad de agradar o complacer al público:

Las damas no desdigan de su nombre,

$y$, si mudaren traje, sea de modo

que pueda perdonarse, porque suele

el disfraz varonil agradar mucho.

vv. $280-283$

De la popularización de dicho recurso da cuenta Jean Canavaggio:

No hay comediógrafo importante en cuyo caudal dramático no se compruebe, al menos una vez, la presencia de algún disfrazado.

Canavaggio, 1978: 135

Para darse cuenta de la enorme popularidad que alcanza la utilización del disfraz varonil en el teatro, baste decir que, de las 460 comedias que escribió Lope de Vega, este recurso aparece en 113, es decir, casi en la cuarta parte de su producción dramática. Tirso de Molina lo utiliza en veintiuna de sus comedias. También lo utiliza Juan Ruiz de Alarcón. En cuanto a Calderón de la Barca, de las 105 comedias que escribió, en siete de ellas aparece, distanciándose bastante en proporción con respecto a Lope. El Cervantes 
dramaturgo tampoco va a ser ajeno al disfraz varonil $y$, si contamos sus diez obras teatrales (ocho comedias más las dos clasicistas, Numancia y Los tratos de Argel), aparece en dos ocasiones.

\subsection{El disfraz varonil en los dramaturgos}

Si analizamos el uso del disfraz varonil en los Siglos de Oro, observamos que ya los primeros dramaturgos se sirvieron de este recurso. Por ejemplo, Celia, en la Comedia del degollado, de Juan de la Cueva, manifiesta una clara predilección por las mujeres fuertes que defienden a ultranza su virginidad o su casto amor. Lo mismo sucede con Semíramis, en La gran Semíramis, y Flaminia, en Atila furioso, ambas de Virués, que aparecen en traje masculino y adoptando un nombre masculino. Mira de Amezcua también utiliza el recurso en La Fénix de Salamanca.

Especialmente interesante es el uso que hace de este recurso Tirso de Molina en Don Gil de las calzas verdes. En esta comedia se nos presenta a una sagaz mujer, doña Juana, que urde mil tramas y engaños para lograr hacer regresar a su ingrato amante. El móvil de todas sus acciones no será el honor, sino el amor, lo que permite analizar una faceta particular de la vida de la mujer: su comportamiento cuando está enamorada. La mujer se presenta aquí como el terrible enemigo del hombre en los asuntos amorosos, capaz de grandes maquinaciones -entre ellas, vestirse de varón- para alcanzar sus propósitos. Sobre el personaje femenino, Juana, se construye toda la obra. Ella traza los enredos y maneja la vida del resto de los personajes de la obra.

La comedia plantea pocos problemas conceptuales. No es una teoría filosófica lo que quiere exponer Tirso de Molina. Solo desea analizar una de las facetas de la personalidad de la mujer: su actuación cuando se halla enamorada y su enamorado la ha abandonado. En el texto, lo fundamental no es el mensaje, el contenido, sino los elementos anecdóticos, el enredo, la diversión, los cambios de caracterización de la protagonista (el vestirse de hombre) y las situaciones que se generan.

El recurso del disfraz varonil vuelve a ser utilizado por Tirso de Molina en El vergonzoso en palacio. En esta obra aparecen las dos hijas del duque de Avero, Madalena y Serafina. Esta última, a finales de la primera jornada, dirigiéndose a Juana, su acompañante, le indica su naturaleza: 
[...] no te asombre

que aparezca el traje de hombre,

ya que no lo puedo ser.

$$
\text { vv. 736-738 }
$$

El espectador, ante esta noticia, enseguida se percata de que está frente a un tipo de mujer varonil. En este caso concreto, el disfraz se utiliza para evitar someterse a la dominación matrimonial del hombre.

El mismo recurso es utilizado en La moza del cántaro, de Lope de Vega, obra donde nos encontramos con el personaje de María, que adopta la estrategia del disfraz varonil como sistema de defensa, es decir, para defenderse de los hombres "depredadores".

La técnica del disfraz varonil vuelve a aparecer en la última comedia de enredo y de capa y espada de Lope, Las bizarrías de Belisa (1634). En el acto III, el Conde y Fernando ven a "dos hombres"que toman por galanes de Lucinda (vv. 1922 1927), cuando en realidad se trata de Finea y Belisa, que iban hasta "con sombreros de plumas y ferreruelos con oro y dos pistolas".

\section{FINEA}

¿Tú a la puerta de Lucinda

con estos necios disfraces?

Considera lo que haces,

por más que el amor te rinda,

que si nos hallan ansí,

nos habemos de perder

vv. 1936-1941

\section{BELISA}

En viendo que soy mujer,

qué podrán pensar de mí?

$$
\text { vv. 1942-1943 }
$$

Una bella Rosaura, en hábito de hombre, irrumpe violentamente al inicio de la obra de Calderón, La vida es sueño. Va acompañada por el gracioso Clarín, y nos cuenta que ha venido hasta Polonia con el propósito de vengarse de su prometido Astolfo, quien la abandonó. Es un disfraz varonil adoptado por abandono del amante, sin querer indicarnos nada más profundo, pues la profundidad de esta obra reside en todo lo que le sucede a su verdadero protagonista, Segismundo. Rosaura aparece desde el primer momento disfrazada de hombre (no es que se disfrace en el intermedio de la obra y lo 
sepamos), pues ya en la primera acotación que ofrece Calderón, se avisa a los lectores del origen de Rosaura:

(En las montañas de Polonia)

Salen en lo alto de un monte ROSAURA, en hábito de hombre, de camino, y en representando los primeros versos va bajando.

Si no leemos la acotación, no sabemos que se trata de un "disfraz varonil"; lo único que percibimos, como espectadores, es la presencia de dos hombres en escena que van caminando. Pero para hacernos ya desde el primer momento partícipes del engaño, Calderón pone en el verso 13, en boca de Rosaura, las palabras "ciega y desesperada", dos adjetivos femeninos que avisan al público del engaño y lo hacen partícipe de él desde el principio. Y, por si no ha quedado del todo claro, en el verso 45 Clarín la llama "señora": "Mas, ¿qué haremos, señora?". Eso sí, frente a Segismundo, ella misma utiliza ya los adjetivos masculinos que "delatan"que es un hombre como él:

Si consuelo puede ser

del que es desdichado, ver

a otro que es más desdichado

vv. $258-260$

Es decir, Calderón nos indica, desde el primer momento, que estamos ante un disfraz varonil. El engaño lo encontramos cuando los demás personajes que aparecen en la obra no reconocen ese disfraz varonil: ellos son los verdaderos engañados.

En resumen, los ejemplos anteriores ponen de manifiesto que los motivos que llevaban a los dramaturgos a usar el recurso del disfraz varonil eran múltiples y muy variados. Ahora bien, el objetivo común de todos ellos era crear una comedia de enredos con la intención de agradar al público y no tanto de reivindicar los derechos que se negaban a las mujeres de la época. A continuación, analizaremos el uso del mismo recurso por parte de las dramaturgas de los Siglos de Oro para demostrar que los objetivos que ellas perseguían eran claramente diferentes a los que buscaban sus coetáneos hombres.

\subsection{El disfraz varonil en las dramaturgas: Ana Caro}

En las obras teatrales escritas por mujeres en los Siglos de Oro también encontramos el recurso al disfraz varonil. La mujer o heroína de estas obras 
teatrales debe saber manejar a la perfección ambos códigos, el masculino y el femenino, y al dominarlos demuestra que ninguno de ellos es superior al otro, de lo que se infiere que la supremacía de un género sobre otro no es más que una racionalización construida a priori. Lo que se proponen las dramaturgas es cuestionar a través de sus obras los convencionalismos a que se deben someter si quieren escribir, criticando con sofisticada ironía dichas convenciones, sin menoscabo de que sus propias obras gocen de todos los elementos y características típicos de las comedias masculinas, haciendo ingeniosos ensayos femeninos sobre la comedia masculina de la época. Un ejemplo destacado del uso del disfraz varonil lo encontramos en la obra de Ana Caro Valor, agravio y mujer.

Ana Caro utiliza el recurso del disfraz varonil cuando hace aparecer en escena a Leonor vestida de hombre (tomará entonces el nombre de Leonardo) para vengar la deshonra que le ha infringido don Juan. A causa de esta deshonra, Leonor vestida de hombre buscará a don Juan por Portugal y Flandes, hasta dar con él. Una vez que consigue que don Juan declare a Leonardo (que es ella disfrazada) que aún ama a Leonor, se desenmascara todo y se casan, presentando así el típico final feliz al que nos tienen acostumbrados todas las comedias de la época y que nos hace pensar que, después de todo, la mujer retorna al rol que el hombre tenía reservado para ella.

Una lectura detenida de Valor, agravio y mujer nos hace suponer que su autora está lanzando un mensaje. En la obra aparecen los personajes prototípicos de esta clase de comedia, sin embargo, "el disfraz que convierte a Leonor en Leonardo consigue transformar a los personajes que la rodean"(Risco Suarez, 2005) e incluso a ella misma. Parece que el vestido masculino le ha dado mayor fuerza y energía. De hecho, un pasaje decisivo en la obra lo constituyen los versos 508 510, en los que Leonor habla sobre su personalidad:

[...] engáñaste si imaginas,

Ribete, que soy mujer;

mi agravio mudó mi ser

$$
\text { vv. } 508-510
$$

Con esta última frase ("mi agravio mudó mi ser"), la autora quiere indicarnos otras posibilidades que van más allá de la simple utilización de un disfraz varonil en escena para deleitar al público. Nos hallamos ante una afirmación de identidad, ante un cuestionamiento al más puro estilo 
existencialista. La protagonista ya no duda: su ser se ha "mudado"por ese agravio sufrido y lo plantea abiertamente al público a través de la conversación con su criado. El agravio sufrido le hace mudar de traje, de nombre y de ser.

Este comportamiento de Leonor contrasta claramente con el de Serafina, en El vergonzoso en palacio de Tirso de Molina. Serafina sabe que se ha vestido de hombre, pero no se cuestiona en absoluto su personalidad: "no te asombre / que aparezca en traje de hombre / ya que no lo puedo ser". Estamos aquí, por tanto, ante una simple utilización del disfraz varonil como mera diversión, sin ir más allá, algo que no sucede en la obra de Ana Caro.

$\mathrm{Si}$ analizamos la obra de Ana Caro, en un principio parece que Leonor se disfraza de hombre para vengar el agravio (parte del título de la obra) de don Juan:

En este traje podré cobrar mi perdido honor.

vv. $464-465$

Hasta aquí todo es normal, pues, como hemos visto, el artificio de disfrazarse de hombre para vengar el honor perdido es muy frecuente en las comedias de los Siglos de Oro. Sabemos que la protagonista es una mujer llena de coraje, pues recorre sola "medio mundo"para intentar vengar su honor mancillado, y parece que el traje no añade nada a su decisión de tomar venganza; pero el público debe creer que sí la ha transformado. Por eso Ribete se dirige a ella en este tono:

Oyéndote estoy,

y, ipor Cristo! Que he pensado

que el nuevo traje te ha dado

alientos

vv. $504-507$

Leonor quiere recobrar su honor, un honor que don Juan le ha arrebatado engañándola, y por eso lo persigue, para conseguir vengarse. Según las normas de la época, esta defensa debería hacerla -rigiéndose por el código del honor- el marido, el padre o el hermano, pero en ningún caso una mujer. Por esa razón, la autora disfraza a Leonor, para que con esa nueva identidad pueda vengar por sí misma el honor mancillado.

Ahora bien, lo que nos interesa en la obra de Ana Caro no es el uso del disfraz como recurso dramático habitual en la época. Lo verdaderamente 
importante aquí es que, con el disfraz, la autora intenta ridiculizar algunas prácticas que se consideraban típicamente masculinas, riéndose de ese código del honor tan cerrado en el que el único que puede defender es el hombre. Leonor sí que tenía un personaje masculino que defendiese o vengase su honor amancillado, su hermano, pero la autora lo sitúa lejos de ella, y de este modo lo anula en la faceta o rol de vengador, para que, a los ojos del espectador, la protagonista parezca aún más fuerte, pues, teniendo quien la defienda, no se lo piensa ni un momento y decide defender ella misma su honor mancillado. Leonor no necesita a ningún hombre que la defienda:

LEONOR:

Ribete, turbada estoy

RIBETE:

¿De qué?

\section{LEONOR:}

De ver a mi hermano.

$$
\text { vv. } 623-625
$$

Hay en esta actitud una reivindicación solapada por parte de la autora para hacernos ver que hombres y mujeres tienen los mismos derechos y las mismas obligaciones: estamos ante el valor de una mujer a la hora de vengar su agravio.

Leonor, por tanto, se comporta como un hombre: ella sola es capaz de hacer lo que haría un hombre. Y, por supuesto, puede hablar como hablaría un hombre. De hecho, es en la utilización del lenguaje donde mejor se pueden percibir las consecuencias del disfraz varonil. Las dramaturgas de los Siglos de Oro utilizan un lenguaje muy del gusto de la época barroca, manejando a la perfección las convenciones teatrales en lo que a lenguaje se refiere. Esa autoconciencia lingüística se refleja muy bien en el largo monólogo que hace Leonor con el lenguaje propio de los galanes, en el que planea con firmeza su determinación de recuperar el honor perdido: dándose ánimos a sí misma hasta conseguir vengar la ofensa recibida:

LEONOR:

(...) Y, ijuro por los azules

velos del cielo y por cuantas

en ellos se miran luces,

que he de morir o vencer, 
sin que me den pesadumbre

iras, olvidos, desprecios,

desdenes, ingratitudes,

aborrecimientos, odios!

vv. 871 y ss.

Otro buen ejemplo de uso masculino del lenguaje lo encontramos en el largo parlamento que hace Leonor (vestida de Leonardo) ante Estela, diálogo riquísimo en figuras literarias, estructuras bimembres cultistas y reiteraciones anafóricas que son las que caracterizarán el galanteo culto y falso de Leonor/Leonardo a Estela. Estas son sus palabras:

\section{LEONOR:}

Mi silencio, hermosa Estela, mucho os dice sin hablar, que es lengua el afecto mudo que está confesando ya los efectos que esos ojos solo pudieron causar, soles que imperiosamente de luz ostentando están entre rayos y entre flechas, bonanza y serenidad, en el engaño, dulzura, extrañeza en la beldad, valentía en el donaire y donaire en el mirar vv. 959 y ss.

El criado es quien llama la atención sobre el talento poético de su señora, al elogiar la destreza con que ha resuelto la dificultad del lenguaje artificioso de los hombres:

RIBETE:

Aquí gracia y después gloria, amén, por siempre jamás.

¡Qué difícil asonante buscó Leonor! No hizo mal;

vv. 1939 y ss.

También Estela se asombra de lo que acaba de oír: 


\section{ESTELA:}

Don Leonardo, bastan ya

las lisonjas, que imagino

que el ruiseñor imitáis, que no canta enamorado

de sus celos al compás,

porque siente o porque quiere,

sino por querer cantar

$$
\text { vv. } 1046 \text { y ss. }
$$

Lo que dice el galán responde a meras convenciones retóricas, presentes en cualquier comedia. La autora lo acusa así de no seguir sus propios sentimientos y de querer solo lucir sus destrezas verbales. Es una crítica de lo viejo y masculino en el teatro, como reflejan los versos siguientes en boca de Estela y Leonor respectivamente:

ESTELA:

¿De qué sirven retóricos colores?

Ya confesáis su amor vv. $1673-1674$

\section{LEONOR:}

¡Fáciles paradojas

intimas, don Leonardo, a mis congojas!

vv. 1793-1794

Ana Caro y las dramaturgas de los Siglos de Otro, en general, no se limitan a denunciar este tipo de lenguaje. Pretenden demostrar que ellas pueden manejarlo en beneficio propio, llegando a provocar la admiración en personajes masculinos:

\section{LUDOVICO:}

Metáfora curiosa

ha sido Estela, comparar la rosa

a don Juan por su gala y bizarría

$$
\text { vv. } 1759-1761
$$

DON JUAN:

¡Sofístico argumento!

$$
\text { v. } 1783
$$


En conclusión, en la obra de Ana Caro, Leonor ofrece una transgresión de papeles que le permite vivir situaciones prohibidas: vengar su honor, enamorar... Se trata de una verdadera masculinización física y lingüística que le permite ocupar un espacio público masculino, por lo que puede ejercer acciones impropias de su género inicial y, sobre todo, utilizar estrategias comunicativas propias de hombres (retórica excesiva para enamorar, lenguaje directo e incisivo para batirse en duelo...). En esa actitud podemos ver una reivindicación solapada por parte de la autora, que intenta demostrar que hombres y mujeres tienen los mismos derechos y las mismas obligaciones. Ana Caro viste a Leonor de hombre para que la crítica no sea tan fuerte. El disfraz varonil sirve, por tanto, como recurso para suavizar la crítica, para que el ataque al sistema de valores establecido y aceptado en la época no resulte tan directo.

\section{Conclusiones}

La situación de la mujer en los siglos XVI y XVII queda reflejada en la literatura en general, y en el teatro en particular. Los personajes femeninos de las comedias siguen estrictamente los imperativos de comportamiento marcados por la sociedad del momento. Para intentar romperlos, las mujeres deben recurrir, entre otras cosas, a la estrategia del cambio de sexo: el disfraz varonil. Este travestismo, androginia o galán fingido, les permite introducirse en un mundo poblado de hombres, en su mentalidad y en sus costumbres. La mujer en el teatro de los Siglos de Oro no se viste de hombre porque sí; lo hace, en la mayoría de los casos, por un motivo particular, que suele estar relacionado con comportamientos "masculinos". Vestida de hombre, la mujer puede recurrir a la violencia, acercarse a la cultura, batirse en duelo o utilizar expresiones no adecuadas para las féminas. Solo travistiéndose, puede la mujer expresar su odio, su furia o su sed de venganza, ya sea mediante el lenguaje o mediante los hechos.

Aunque el recurso del disfraz varonil se puede encontrar, como hemos visto, tanto en los dramaturgos como en las dramaturgas, las motivaciones no son las mismas en uno y otro caso. Comediógrafos como Lope, Tirso, Calderón, etc. se sirven del galán fingido para crear una comedia de enredos y agradar al público que iba al teatro. En las dramaturgas, en cambio, el recurso se utiliza como medio para rebelarse contra los estereotipos de la época, que vetan a las mujeres una serie de comportamientos. Las comediógrafas de los Siglos de Oro no se resignan a recibir un trato desigual 
con respecto a los hombres; por ello critican esas diferencias poniendo en entredicho, explícita o implícitamente, los contenidos y los modos de hacer teatro por parte de los hombres. De ahí que aprovechen el disfraz varonil para hacer creer al público que son hombres y que actúan como se espera de ellos. Al producirse la agnición, el público percibe que lo que un hombre hace lo ha hecho una mujer, de modo que las dramaturgas consiguen sus objetivos.

La obra de Ana Caro, como la de otras autoras contemporáneas, critica y cuestiona la autoridad masculina. Ironiza sobre las reglas establecidas por la sociedad en que le ha tocado vivir y, sobre todo, ridiculiza algunas actitudes consideradas como valores típicamente masculinos. Leonor se rebela contra la opinión admitida de que las mujeres no son valerosas como los hombres y le da la vuelta: ella sí que es valiente.

\section{Bibliografía}

1. Baranda, N. (2004): Las dramaturgas del XVII. En I. Arellano (ed.), Paraninfos, segundones y epígonos de la comedia del Siglo de Oro. Madrid: Anthropos.

2. Calderón de la Barca, P. (1636): La vida es sueño. Madrid, Espasa-Calpe 1997, edic. de Evangelina Rodríguez Cuadros.

3. Canavaggio, J. (1978): Los disfrazados de mujer en la comedia en La mujer en el teatro y la novela del siglo XVII. En Actas del II coloquio sobre teatro español, GESTE (Toulouse, 1617 de noviembre de 1978).

4. Caro, A. (1628): Valor, agravio y mujer. Madrid: Biblioteca de Escritores Castalia, Instituto de la mujer [edición de Lola Luna, 1993].

5. Cotarelo y Mori, E. (1997 [1904]): Bibliografía de las controversias sobre la licitud del teatro en España. Granada: Universidad de Granada.

6. Cueva, J. de la (1588, Sevilla): La muerte del rey don Sancho y reto de Zamora. Comedia del degollado. Universidad de León, León 1997.

7. De Zabaleta, J. (1653): Errores celebrados. Madrid: Espasa-Calpe [edición de David Hershberg, 1972].

8. De Zayas y Sotomayor, M. (1637): Novelas amorosas y ejemplares, Biblioteca Castro, Madrid, 2001.

9. Ferrer Valls, T. (2006): Del oratorio al balcón: escritura de mujeres y espacio dramático. Espacios domésticos en la literatura áurea. Ínsula, 714: 8-12.

10. Fray Luis de León (1950 [1583]): La perfecta casada. Madrid: Atlas.

11. Lope de Vega Carpio, F. (1609): Arte nuevo de hacer comedias, Cátedra, 2008.

12. Lope de Vega Carpio, F. (1627): La moza del cántaro. Ministerio de educación y cultura, Madrid, 2008

13. Lope de Vega Carpio, F (1634): Las bizarrías de Belisa. Cátedra, Madrid, 2004. 
14. Lujan, P. (1990 [1550]): Los coloquios matrimoniales del licenciado Pedro Luján. Madrid: Anejos del BRAE [edición de Asunción Rallo Gruss].

15. Mira de Amescua, A. (1653): La fénix de Salamanca. Biblioteca Virtual Miguel de Cervantes, Alicante, 1999.

16. Ortiz, M. (2005): Yo, (i) soy quien soy (?): la mujer eén hábito de comedia en Valor, agravio y mujer. En Vanderbilt. e-Journal of Luso-Hispanic studies, vol. 2, University of South Florida.

17. Risco Suárez, N. (2005): Ana Caro de Mallén, la musa sevillana: una periodista feminista en el Siglo de Oro. Revista Científica de Información y Comunicación, 2: 105120.

18. Tirso de Molina (1993 [1635]): Don Gil de las Calzas Verdes. Madrid: Castalia.

19. Tirso de Molina (1971 [1606]): El vergonzoso en Palacio. Madrid: Castalia [edición de Francisco Ayala].

20. Torres Naharro, B. (1516): Comedias Soldadesca, Tinelaria, Himenea. Castalia, Madrid, 1990

21. Virués, C. de (1580-1590): Obras trágicas y líricas del Capitán Cristóval de Virués. Madrid, Alonso Martín - Cátedra, 2003.

22. Vives, J.L. (1990 [1492-1540]): Instrucción de la mujer cristiana. Madrid: FUE. 